\title{
Prevalence of maternal periodontitis and its association with preterm and low birth weight infants: a hospital-based study
}

\author{
Priyanka S. ${ }^{1}$, Sowmya Koteshwara ${ }^{1 *}$, Anitha Subappa ${ }^{2}$
}

\begin{abstract}
${ }^{1}$ Department of Obstetrics and Gynecology, JSS Medical College and Hospital, Mysore, Karnataka, India
${ }^{2}$ Department of Periodontology, JSS Dental College and Hospital, Mysore, Karnataka, India
\end{abstract}

Received: 03 April 2019

Accepted: 09 April 2019

\section{*Correspondence:}

Dr. Sowmya Koteshwar,

E-mail: sowsheshu@gmail.com

Copyright: () the author(s), publisher and licensee Medip Academy. This is an open-access article distributed under the terms of the Creative Commons Attribution Non-Commercial License, which permits unrestricted non-commercial use, distribution, and reproduction in any medium, provided the original work is properly cited.

\begin{abstract}
Background: Preterm deliveries and low birth are important causes of infant mortality and morbidity. The aim of this study was to evaluate the association between maternal periodontitis and preterm and low birth weight at delivery and to correlate the severity of periodontitis with obstetric outcome.

Methods: This was a prospective observational study conducted in Outpatient Department of Tertiary Care Hospital. Pregnant women who had regular antenatal checkup at were screened clinically for periodontitis. Those who were diagnosed with periodontitis and satisfied the inclusion and exclusion criteria were considered as cases $(n=45)$ and equal number of pregnant women without periodontal disease $(n=45)$ were included in the study as controls. These patients were followed up and gestational age at delivery and baby's birth weight was noted and correlated to the maternal periodontal status.

Results: The prevalence of maternal periodontitis was found to be $11.4 \%$. Mean age, socioeconomic status and educational status was comparable. $33.3 \%, 40 \%$ of the cases v/s $17.8 \%, 24.4 \%$ of controls had preterm deliveries and LBW infants respectively. $26.8 \%$ of cases with mild periodontitis and all cases of moderate and severe periodontitis had preterm birth. Additionally, $34.1 \%$ of cases with mild periodontitis and all cases with moderate and severe periodontitis had low birth weight infants $(\mathrm{p}=0.02)$.

Conclusions: Maternal periodontitis is found to be associated with preterm and low birth weight deliveries. The severity of periodontitis is inversely related to gestational age at delivery and birth weight of infant. Thus, periodontitis is suggested to be a modifiable risk factor for preterm and low birth deliveries.
\end{abstract}

Keywords: Low birth weight, Maternal periodontitis, Preterm delivery

\section{INTRODUCTION}

Preterm birth is defined as babies born alive before 37 weeks of pregnancy are completed. ${ }^{1}$ Preterm birth and being small for gestational ages (SGA) are the reasons for low-birth-weight (LBW), which is defined as live born infants with birth weight less than 2500 gms. LBW contributes to $60 \%$ to $80 \%$ of all neonatal deaths. The global prevalence of LBW is $15.5 \%$, which amounts to about 20 million LBW infants born each year, $96.5 \%$ of them in developing countries. ${ }^{2}$

Multiple factors have been associated with LBW. Some of these known risk factors in mothers for LBW include anemia, preeclampsia, genitourinary infections, extremes of maternal age, previous preterm delivery, inadequate prenatal care, low pre pregnancy weight, multiple gestations, diabetes mellitus, low socioeconomic status 
(SES), short stature, illicit drug use, cigarette smoking and excessive alcohol consumption.

Despite the many advances in medicine, the rate of preterm birth has not significantly decreased over the past several decades. Consequently, the identification of risk factors for preterm birth which are amenable to intervention would have far-reaching and long-lasting effects. Researchers have found that distant infections like periodontal diseases are also responsible for preterm low birth weight deliveries.

Periodontal diseases (PD) include a group of chronic inflammatory disease that affect the supporting structures of the teeth involving complex inflammatory interactions with the host, leading to potential tooth loss. Periodontitis is caused predominantly by gram-negative, anaerobic, and microaerophilic bacteria that colonize in the sub gingival area and cause local and systemic elevations of proinflammatory prostaglandins and cytokines. Thus, periodontitis is suggested to be a modifiable risk factor for preterm low birth weight. ${ }^{3}$

Prematurity and LBW contribute to many medical and social problems for the child, such as neurodevelopmental problems, congenital anomalies, learning disabilities. India is home to nearly $40 \%$ of all LBW babies in the developing world. ${ }^{4}$ Early diagnosis and treatment of maternal periodontitis can decrease the incidence of preterm birth and low birth weight to a great extent. A landmark study conducted by Offenbacher $\mathrm{S}$ et al, indicated that periodontal diseases represent a previously unrecognized and clinically significant risk factor for low birth weight as a consequence of either preterm labour or preterm PROM. ${ }^{5}$

Offenbacher $\mathrm{S}$ et al, a studied a group of 48 women between cases and controls, found that the case group, i.e., mothers of preterm had worse periodontal disease than control group, finding them in higher levels of PGE2 and IL-lb, as well as periodontal pathogens. ${ }^{6}$ In this study, they established that maternal infections during pregnancy perturb the normal cytokine and hormoneregulated gestation, sometimes resulting in preterm labor, preterm premature rupture of membranes, and preterm low birth weight (PLBW). They suggested a doseresponse relationship for increasing GCF-PGE2 as a marker of current periodontal disease activity and decreasing birth weight.

Tellapragada $\mathrm{C}$ et al, conducted a hospital based prospective study among 790 pregnant women and evaluated the risk factors for preterm birth and low birth weight. ${ }^{7}$ Rates of PTB and LBW in the study population were $7.6 \%$ and $11.4 \%$, respectively. Previous preterm delivery, periodontitis, oligohydramnios, presence of Nugent's intermediate vaginal flora, gestational diabetes mellitus and maternal height $<1.50 \mathrm{~m}$ were risk factors for PTB, while periodontitis, gestational hypertension, maternal height $<1.50 \mathrm{~m}$ and genital infection during later stages of pregnancy were independent risk factors for LBW.

Gharib MN et al, conducted a prospective study in Tanta University Hospital among 200 pregnant women with singleton pregnancy in the first stage of labor with intact membranes. ${ }^{8}$ They were divided into 2 groups-one with preterm low birth weight deliveries and one with term normal birth weight deliveries. Periodontal evaluation and levels of IL- 6 and TNF- $\alpha$ were measured in gingival cervicular fluid, maternal serum and amniotic fluid using ELISA technique. They found a significant association between chronic periodontal disease and preterm low birth weight infants. They also found that IL-6 and TNF$\alpha$ in both the gingival cervical fluid and maternal serum were significant markers.

In a case control study, conducted by Jacob PS et al, among 340 postnatal mothers (2014), preterm labor was present in $48.2 \%$ of the mothers with periodontitis as compared to $14.1 \%$ of the control. LBW cases had a significantly worse periodontal status than the controls, having an odds ratio of $2.94 .^{4}$ The multivariate logistic regression model demonstrated that periodontal disease is a significant independent risk factor for preterm labour and LBW. Other factors showing significant associations with LBW were pre-eclampsia, preterm labor, and vaginal type of delivery.

A study conducted by Lopez $\mathrm{NJ}$ et al, among 870 pregnant women in Chile found the incidence of preterm/ low birth weight in the treatment group to be $2.14 \%$ compared to $6.71 \%$ in the control group. ${ }^{9}$ Hence, they concluded that periodontal therapy reduced the preterm and low birth weight rates in pregnant women with periodontitis.

However, a study by Martinez-Martini et al, suggested that preterm birth is a multifactorial condition and that periodontitis and presence of periodontal disease are not sufficient to trigger preterm deliveries. ${ }^{10}$

Thus, this study was undertaken to determine the association between maternal periodontitis and preterm and low birth weight deliveries.

The objectives of the study was to determine the prevalence of periodontitis among pregnant women attending ANC clinic, to find the association between maternal periodontitis and preterm and/or low birth weight at delivery and to correlate severity of periodontitis with obstetric outcome.

\section{METHODS}

It was a prospective observational study. Pregnant women attending ANC clinic in tertiary care hospital during the period of October 2016 to July 2018, fulfilling all inclusion and exclusion criteria were included in the study. 
The prevalence of maternal periodontitis was $10 \% .^{4}$ Sample size was calculated using the formula $\mathrm{Z} 2 \mathrm{pq} / \mathrm{d} 2$, where $\mathrm{Z}$ is a constant $1.96, \mathrm{p}$ is proportion of prevalence taken as $10 \%(0.1), q=(1-p)=90 \%(0.9)$ and $d$ is precision taken as absolute precision. Using the above formula and estimating a 5\% drop out rate the sample size was calculated as 75 antenatal women.

\section{Inclusion criteria}

Normal booked cases with singleton pregnancy between 20-30 weeks of gestation in JSS Hospital, Mysore, Karnataka, India.

\section{Exclusion criteria}

- $\quad$ Pregnancy complicated with anemia, preeclampsia, diabetes mellitus,

- $\quad$ Extremes of age groups $(<18$ or $>35)$,

- Previous preterm delivery,

- Multiple gestation,

- Tobacco/alcohol addiction,

- Antibiotic usage in last 3 months.

\section{Procedure}

After counseling, an informed valid consent was obtained from every case. All patients included in the study were subjected to history taking, general and obstetric examination. Data was collected in a validated questionnaire. Periodontal evaluation included review of a person's medical and dental history, followed by a full mouth periodontal examination. The clinical examination included clinical attachment levels and probing depths on 6 sites per tooth. Clinical attachment levels were determined using a manual probe, bleeding index, plaque index and gingival index was recorded and the Community Periodontal Index of Treatment Needs (CPTIN) Score was calculated. Patients were divided into periodontitis group and periodontally healthy group. Severity of periodontitis was also graded. Both groups of patients were followed up and gestational age at delivery and baby's birth weight will be noted and correlated to the maternal periodontal status.

\section{Statistical analysis}

The data obtained was collected on Microsoft Excel and analysed using SPSS Microsoft version 21. The statistical methods used were Descriptive Stastistics (Mean, SD, Frequency, Percentage), Chi square test, Cramer's V, One-way ANOVA and One sample t test.

\section{RESULTS}

During study period a total of 500 pregnant women were included in study, out of which 57 cases of periodontitis were identified. Out of the 57 cases of periodontitis, 45 cases satisfied the inclusion and exclusion criteria and were included as cases (ANW with periodontitis) and 45 subjects (who satisfied the inclusion and exclusion criteria) from the remaining 443 pregnant women were taken as controls (ANW without periodontitis). They were followed up and gestational age at delivery and baby's birth weight were recorded. Out of the total, 500 pregnant women who were examined, 57 (11.4\%) pregnant women were identified with periodontitis giving a prevalence of $11.4 \%$. Mean age in cases was $25.67 \pm 4.5$ yrs. Mean age in controls was $25.44 \pm 4.3$ yrs. There was no statistically significant mean age difference found between cases and controls.

Majority of the subjects in cases and controls were educated up to high school education $(64.4 \%$ vs $62.2 \%)$ and belonged to class 2 soccio-eccnomic status (64.4\% vs $66.7 \%$ ). Majority of the subjects in cases $51.1 \%$ were multigravida and $48.9 \%$ were primigravida. Majority of subject in controls $51.1 \%$ were primigravida and $48.9 \%$ were multigravida. $\mathrm{P}$ Value was 0.833 and there was no statistically significant difference found between parity among cases and control (Table 1).

Table 1: Parity among cases and controls.

\begin{tabular}{|c|c|c|c|c|}
\hline \multirow{2}{*}{ Parity } & \multicolumn{2}{|l|}{ Group } & \multirow{2}{*}{ Total } & \multirow{2}{*}{ P value } \\
\hline & Cases & Controls & & \\
\hline \multirow{2}{*}{ Primi } & 22 & 23 & 45 & \multirow{6}{*}{0.833} \\
\hline & $48.9 \%$ & $51.1 \%$ & $50.0 \%$ & \\
\hline \multirow{2}{*}{ Multi } & 23 & 22 & 45 & \\
\hline & $51.1 \%$ & $48.9 \%$ & $50.0 \%$ & \\
\hline \multirow{2}{*}{ Total } & 45 & 45 & 90 & \\
\hline & $100.0 \%$ & $100.0 \%$ & $100.0 \%$ & \\
\hline
\end{tabular}

About $33.3 \%$ of the cases gestational age at delivery $<37$ weeks (preterm infants) as compared to controls (term infants) $17.8 \% \quad(\mathrm{P}=0.091)$ and there was no statistically significant difference found between gestational age at delivery among cases and controls (Table 2).

Table 2: Gestational age (preterm/term infants) at delivery among cases and controls.

\begin{tabular}{|c|c|c|c|c|}
\hline \multirow{2}{*}{$\begin{array}{l}\text { Gestational } \\
\text { age at } \\
\text { delivery }\end{array}$} & \multicolumn{2}{|l|}{ Group } & \multirow[b]{2}{*}{ Total } & \multirow{2}{*}{$\begin{array}{l}\mathrm{P} \\
\text { value }\end{array}$} \\
\hline & Cases & Controls & & \\
\hline \multirow{2}{*}{$<37$ weeks } & 15 & 8 & 23 & \multirow{6}{*}{0.091} \\
\hline & $33.3 \%$ & $17.8 \%$ & $25.6 \%$ & \\
\hline \multirow{2}{*}{ >37 weeks } & 30 & 37 & 67 & \\
\hline & $66.7 \%$ & $82.2 \%$ & $74.4 \%$ & \\
\hline \multirow{2}{*}{ Total } & 45 & 45 & 90 & \\
\hline & $100.0 \%$ & $100.0 \%$ & $100.0 \%$ & \\
\hline
\end{tabular}

About $40 \%$ of the cases had LBW infants compared to $24.4 \%$ of controls with LBW infants ( $P$ value=0.114). There was no statistically significant difference found between birth weight of infant among cases and controls (Figure 1). 


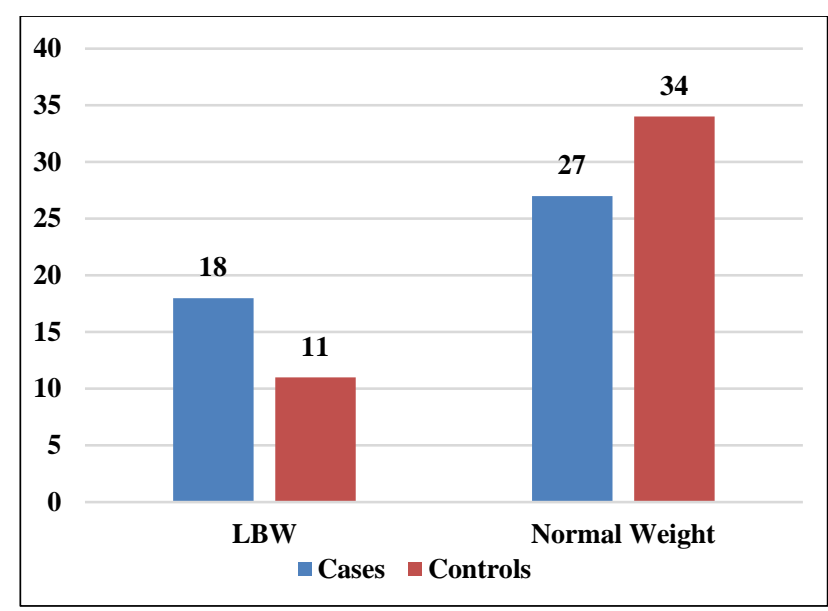

Figure 1: Birth weight infant among cases and controls.

In $26.67 \%$ of cases, infants needed NICU admission as compared to $15.6 \%$ of controls. $\mathrm{P}$ value was 0.438 there was no statistically significant difference (Table 3 ).

Among the cases, $91.1 \%$ had mild periodontitis, $6.7 \%$ had moderate periodontitis and $2.2 \%$ had severe periodontitis (Table 4).
Table 3: NICU admission of infants among cases and controls.

\begin{tabular}{|c|c|c|c|c|}
\hline \multirow{2}{*}{$\begin{array}{l}\text { NICU } \\
\text { admission }\end{array}$} & \multicolumn{2}{|l|}{ Group } & \multirow{2}{*}{ Total } & \multirow{2}{*}{$\begin{array}{l}P \\
\text { value }\end{array}$} \\
\hline & Cases & Controls & & \\
\hline \multirow{2}{*}{ No } & 33 & 38 & 71 & \multirow{6}{*}{0.438} \\
\hline & $73.33 \%$ & $84.4 \%$ & $78.9 \%$ & \\
\hline \multirow{2}{*}{ Yes } & 12 & 7 & 19 & \\
\hline & $26.67 \%$ & $15.6 \%$ & $21.1 \%$ & \\
\hline \multirow{2}{*}{ Total } & 45 & 45 & 90 & \\
\hline & $100.0 \%$ & $100.0 \%$ & $100.0 \%$ & \\
\hline
\end{tabular}

Table 4: Severity of periodontitis among cases.

\begin{tabular}{|lll|}
\hline Severity of periodontitis & Frequency & Percentage \\
\hline Mild & 41 & $91.1 \%$ \\
\hline Moderate & 3 & $6.7 \%$ \\
\hline Severe & 1 & $2.2 \%$ \\
\hline Total & 45 & $100 \%$ \\
\hline
\end{tabular}

About $26.8 \%$ of cases with mild periodontitis and all cases of moderate and severe periodontitis had preterm birth. $\mathrm{P}$ value was 0.004 and there was statistically significant difference found between severity of periodontitis and preterm birth (Table 5 and Figure 2).

Table 5: Severity of periodontitis with term/preterm.

\begin{tabular}{|c|c|c|c|c|c|c|}
\hline \multirow{3}{*}{ Deliveries } & \multicolumn{4}{|l|}{ Periodontitis } & \multirow{3}{*}{ Total } & \multirow{3}{*}{$P$ value } \\
\hline & \multirow{2}{*}{ Controls (Absent) } & \multicolumn{3}{|l|}{ Cases } & & \\
\hline & & Mild & Moderate & Severe & & \\
\hline \multirow{2}{*}{ Preterm } & 8 & 11 & 3 & 1 & 23 & \multirow{6}{*}{0.004} \\
\hline & $17.8 \%$ & $26.8 \%$ & $100.0 \%$ & $100.0 \%$ & $25.6 \%$ & \\
\hline \multirow{2}{*}{ Term } & 37 & 30 & 0 & 0 & 67 & \\
\hline & $82.2 \%$ & $73.2 \%$ & $.0 \%$ & $.0 \%$ & $74.4 \%$ & \\
\hline \multirow{2}{*}{ Total } & 45 & 41 & 3 & 1 & 90 & \\
\hline & $100.0 \%$ & $100.0 \%$ & $100.0 \%$ & $100.0 \%$ & $100.0 \%$ & \\
\hline
\end{tabular}

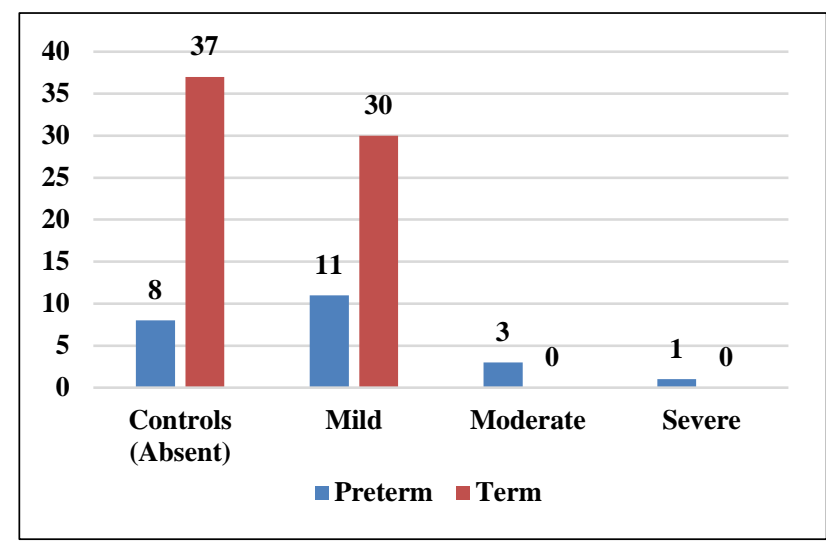

Figure 2: Severity of periodontitis with term/preterm.

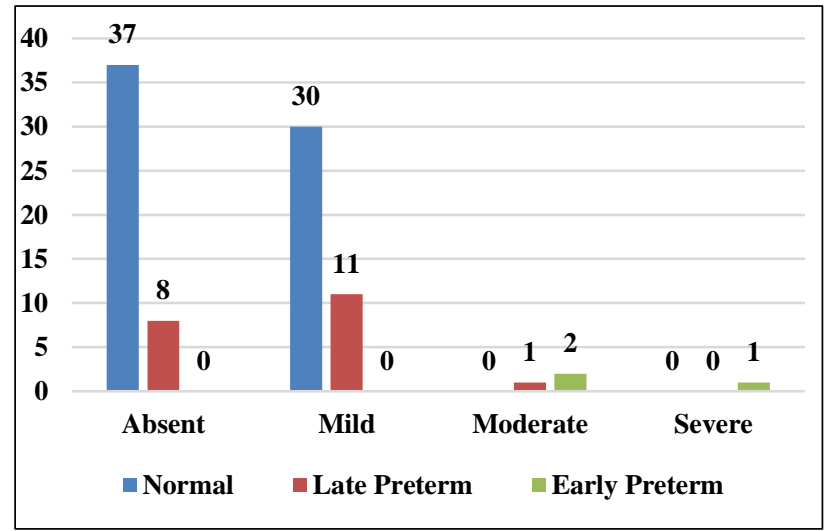

Figure 3: Severity of periodontitis with early/late preterm. 
All cases with severe periodontitis and $66.7 \%$ with moderate periodontitis had early preterm birth. $\mathrm{P}$ value $<0.001$, there was statistically significant difference found between severity periodontitis and prematurity (Table 6 and Figure 3).

Table 6: Severity of periodontitis with early/late preterm.

\begin{tabular}{|c|c|c|c|c|c|c|}
\hline \multirow{3}{*}{ Deliveries } & \multicolumn{4}{|l|}{ Periodontitis } & \multirow{3}{*}{ Total } & \multirow{3}{*}{$P$ value } \\
\hline & \multirow{2}{*}{ Controls (Absent) } & \multicolumn{3}{|l|}{ Cases } & & \\
\hline & & Mild & Moderate & Severe & & \\
\hline \multirow{2}{*}{ Normal } & 37 & 30 & 0 & 0 & 67 & \multirow{8}{*}{$<0.001$} \\
\hline & $82.2 \%$ & $73.2 \%$ & $0 \%$ & $0 \%$ & $74.4 \%$ & \\
\hline \multirow{2}{*}{ Late preterm } & 8 & 11 & 1 & 0 & 20 & \\
\hline & $17.8 \%$ & $26.8 \%$ & $33.3 \%$ & $0 \%$ & $22.2 \%$ & \\
\hline \multirow{2}{*}{ Early preterm } & 0 & 0 & 2 & 1 & 3 & \\
\hline & $0 \%$ & $0 \%$ & $66.7 \%$ & $100 \%$ & $3.3 \%$ & \\
\hline \multirow{2}{*}{ Total } & 45 & 41 & 3 & 1 & 90 & \\
\hline & $100.0 \%$ & $100.0 \%$ & $100.0 \%$ & $100.0 \%$ & $100.0 \%$ & \\
\hline
\end{tabular}

About $34.1 \%$ of cases with mild periodontitis and all cases with moderate and severe periodontitis had low birth weight infants. $\mathrm{P}$ value was 0.02 , there was a statistically significant difference found between severity of periodontitis and birth weight (Table 7 and Figure 4).

Table 7: Severity of periodontitis with low birth weight/ normal weight.

\begin{tabular}{|llllll|}
\multirow{2}{*}{ Birthweight } & Periodontitis & Cases & & Total & P value \\
\cline { 2 - 6 } & Controls (Absent) & Mild & Moderate & Severe & \\
\hline \multirow{2}{*}{ LBW } & 11 & 14 & 3 & 1 & 29 \\
\cline { 2 - 6 } & $24.4 \%$ & $34.1 \%$ & $100.0 \%$ & $100.0 \%$ & $32.2 \%$ \\
\multirow{2}{*}{ Normal } & 34 & 27 & 0 & 0 & 61 \\
\cline { 2 - 6 } & $75.6 \%$ & $65.9 \%$ & $0 \%$ & $0 \%$ & $67.8 \%$ \\
\multirow{2}{*}{ Total } & 45 & 41 & 3 & 1 & 90 \\
\cline { 2 - 6 } & $100.0 \%$ & $100.0 \%$ & $100.0 \%$ & $100.0 \%$ & $100.0 \%$ \\
\hline
\end{tabular}

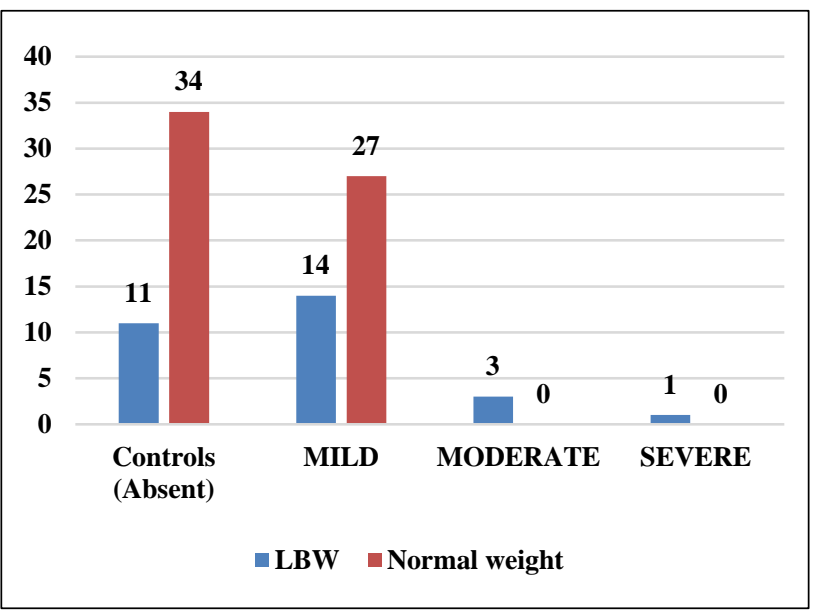

Figure 4: Severity of periodontitis and low birth weight/ normal weight.

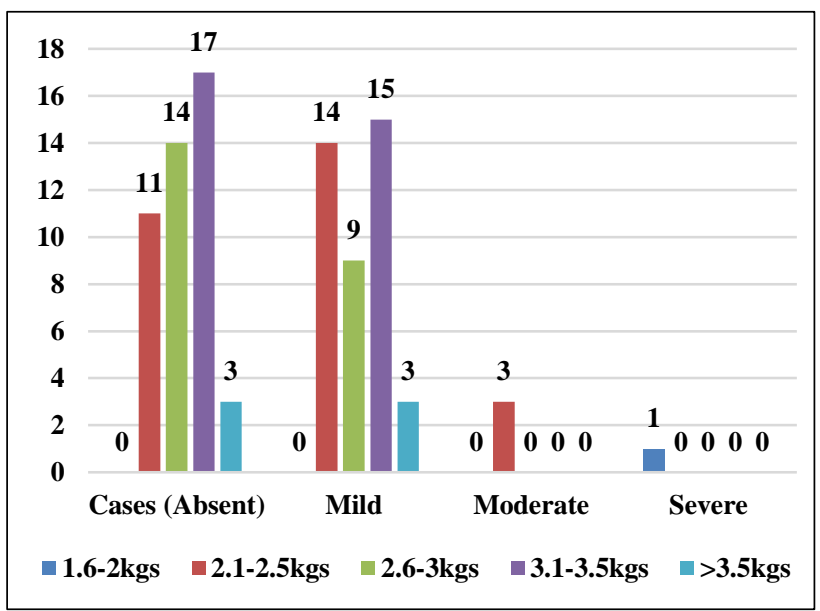

Figure 5: Severity of periodontitis with birth weight. 
$\mathrm{P}$ value $<0.001$, there was statistically significant difference found between severity periodontitis and birth weight (Table 8 and Figure 5). Infants of $19.5 \%$ of cases with mild periodontitis and all cases of moderate and severe periodontitis needed NICU admission. P value was 0.031 , there was a statistically significant difference found between severity of periodontitis and NICU admission of infant (Table 9).

Table 8: Severity of periodontitis with birth weight.

\begin{tabular}{|c|c|c|c|c|c|c|}
\hline \multirow{3}{*}{ Birthweight } & \multicolumn{4}{|l|}{ Periodontitis } & \multirow{3}{*}{ Total } & \multirow{3}{*}{$P$ value } \\
\hline & \multirow{2}{*}{ Cases (Absent) } & \multicolumn{3}{|l|}{ Controls } & & \\
\hline & & Mild & Moderate & Severe & & \\
\hline \multirow{2}{*}{ 1.6-2 kgs } & 0 & 0 & 0 & 1 & 1 & \multirow{12}{*}{$<0.001$} \\
\hline & $0 \%$ & $0 \%$ & $0 \%$ & $100.0 \%$ & $1.1 \%$ & \\
\hline \multirow{2}{*}{$2.1-2.5 \mathrm{kgs}$} & 11 & 14 & 3 & 0 & 28 & \\
\hline & $24.4 \%$ & $34.1 \%$ & $100.0 \%$ & $0 \%$ & $31.1 \%$ & \\
\hline \multirow{2}{*}{$2.6-3 \mathrm{kgs}$} & 14 & 9 & 0 & 0 & 23 & \\
\hline & $31.1 \%$ & $22.0 \%$ & $0 \%$ & $0 \%$ & $25.6 \%$ & \\
\hline \multirow{2}{*}{$3.1-3.5 \mathrm{kgs}$} & 17 & 15 & 0 & 0 & 32 & \\
\hline & $37.8 \%$ & $36.6 \%$ & $0 \%$ & $0 \%$ & $35.6 \%$ & \\
\hline \multirow{2}{*}{$>3.5 \mathrm{~kg}$} & 3 & 3 & 0 & 0 & 6 & \\
\hline & $6.7 \%$ & $7.3 \%$ & $0 \%$ & $0 \%$ & $6.7 \%$ & \\
\hline \multirow{2}{*}{ Total } & 45 & 41 & 3 & 1 & 90 & \\
\hline & $100.0 \%$ & $100.0 \%$ & $100.0 \%$ & $100.0 \%$ & $100.0 \%$ & \\
\hline
\end{tabular}

Table 9: Severity of periodontitis with NICU admission.

\begin{tabular}{|c|c|c|c|c|c|c|}
\hline \multirow{3}{*}{$\begin{array}{l}\text { NICU } \\
\text { admission }\end{array}$} & \multicolumn{4}{|l|}{ Periodontitis } & \multirow{3}{*}{ Total } & \multirow{3}{*}{ P value } \\
\hline & \multirow{2}{*}{ Controls (Absent) } & \multicolumn{3}{|l|}{ Cases } & & \\
\hline & & Mild & Moderate & Severe & & \\
\hline \multirow{2}{*}{ No } & 38 & 33 & 0 & 0 & 71 & \multirow{6}{*}{0.031} \\
\hline & $84.4 \%$ & $80.5 \%$ & $0 \%$ & $0 \%$ & $78.9 \%$ & \\
\hline \multirow{2}{*}{ Yes } & 7 & 8 & 3 & 1 & 19 & \\
\hline & $15.6 \%$ & $19.5 \%$ & $100.0 \%$ & $100.0 \%$ & $21.1 \%$ & \\
\hline \multirow{2}{*}{ Total } & 45 & 41 & 3 & 1 & 90 & \\
\hline & $100.0 \%$ & $100.0 \%$ & $100.0 \%$ & $100.0 \%$ & $100.0 \%$ & \\
\hline
\end{tabular}

\section{DISCUSSION}

Preterm and low birth weight is often considered to be one of the most common obstetric risk factors leading to mortality and morbidity among the newborns. The low birth weight infants are at higher risk of acute and chronic infection in the due course of their lifetime. Fifty-nine percent of neonatal deaths are associated with preterm delivery and birth weight of under $1500 \mathrm{~g}$. Birth weight is considered to be an important determinant of the chances of an infant to survive, grow and mature. ${ }^{11}$ Low birth weight babies are about 20 times, and very low birth weight babies $(<1500 \mathrm{~g})$ are about 80 times more likely to die before their first birthday. ${ }^{11}$

Both periodontal disease and pre-term low birth weight are multifactorial in nature. Over the last two decades extensive historical, experimental, microbiological and epidemiological evidence have reported that periodontal disease is an important risk factor for pre-term low birth weight.

The prevalence of maternal periodontitis in this study was found to be $11.4 \%$. This is found to be similar to a hospital-based study conducted by Tellapragada $\mathrm{C}$ et al, to evaluate the prevalence of clinical periodontitis among South Indian pregnant women, in which the prevalence was found to be $10 \%$. $^{7}$

The incidence of preterm delivery was twice more among the cases when compared with controls. Author could easily conclude that incidence of preterm delivery was more in the cases with periodontal disease when compared with normal pregnant mothers.

Offenbacher S et al, and Collins JW et al, also found that the incidences of preterm delivery were more among the periodontal disease pregnant mothers which was similar 
to this study findings. The incidence of preterm delivery was $33.3 \%$ in cases and $17.8 \%$ in controls in this study. ${ }^{5,12}$

In a similar study done by Jacob PS et al, they found a higher incidence of preterm birth in antenatal women with periodontitis $48.2 \%$ as compared to $14.1 \%$ among controls.

In this study, low birth weight was seen among $40 \%$ of the deliveries in cases group and $24.4 \%$ in control group, which indicated the incidence of low birth weight was more in cases than control, which substantiates the findings of various other studies where low birth weight was also seen more among the cases with periodontal disease. Similar results with more incidence of low birth weight similar to this study findings were also seen in the studies done by Offenbacher S et al, Lopez $\mathrm{NJ}$ et al. In another study by Lewis $\mathrm{M}$ et al, the incidence of low birth weight was $13.5 \%$ in control and $18.9 \%$ in case group, which is contrast to this study findings which was due to effective treatment of the periodontal disease during the course of the pregnancy. $6,13,14$

The NICU admission was seen among $26.7 \%$ of the cases and $15.6 \%$ in control groups, indicating that children born to mothers with periodontal disease had higher incidence of NICU admission than the control group. The infants born to such mothers with periodontal disease usually suffers from any kind of infection and born with low birth weight requiring specialist care hence admitted to NICU for further management of infant. The duration of hospital stay was also found to be more among the cases than controls.

Author found a negative correlation between severity of periodontitis and gestational age at delivery and birth weight. Present study showed a statistically significant decrease in the gestational age at delivery and infant birth weight as the periodontal disease severity increased. The results seen in this study was similar to the study findings of Offenbacher S et al. ${ }^{6}$ In the study done by Dempsey $\mathrm{R}$ et al, also concluded that as the severity of the plaque and gingival infection increases the risk of having a low birth weight and the decreased gestational age of pregnancy is seen but the differences was found to be statistically not significant. ${ }^{15}$ Even in the study done by Romero BC et al, found that a decrease in the average newborn's weight and gestational age was observed as the mother's level of periodontal disease increased and suggested that periodontal disease in pregnant women would be a clinically significant risk factor for preterm deliveries and low birth weight. ${ }^{16}$ The results of this study were concurrent with the findings of Marin CI et al, where the bleeding of gingiva on probing was significantly greater in women with infants weighing less than 2500 gms when compared with infants weighing more than 2500 gms. ${ }^{17}$ Radani $M$ et al, also indicated that the early localized periodontitis of the patient during pregnancy can be regarded as an important risk factor for Preterm birth. ${ }^{18}$

The findings in this study was in contrast to a study conducted by Davenport ES et al, which stated that there was no evidence for any association between the increasing levels of periodontal disease and increased risk of the preterm and low birth weight. ${ }^{19}$

In the study done by Mokeem SA et al, they concluded that periodontal disease was more prevalent in mother's who delivered preterm low birth weight infants than in mothers who delivered term normal weight infants. ${ }^{20}$ This can be explained by the fact that periodontal disease may influence pregnancy outcome by the direct or the indirect effect of periodontal pathogens on the developing fetus.

Dasanayake AP et al, also reported that the mothers who delivered preterm low birth weight infants appeared to have more severe gingivitis than the mothers who delivered term normal birth weight infants. ${ }^{21}$ Even in the same study he concluded that mothers with low birth weight had severe gingivitis when compared to mothers who delivered term normal birth weight infants.

The mechanism of periodontal disease causing PLBW is still unclear, but this association has biologically feasible basis. There is some evidence that women suffering from severe periodontal disease during pregnancy are more prone to experiencing a preterm birth even after considering shared risk factors. Both periodontal disease and preterm delivery have been associated with certain characteristic polymorphisms in genes that code for cytokines 96 . The role of prostaglandins in human labor has been well documented. Increased amniotic fluid concentrations of PGE2 have been shown in term and preterm labor, and the stimulatory effect of PGE2 on myometrium contractility is also well known.

\section{CONCLUSION}

Maternal periodontitis is found to be associated with preterm and low birth weight deliveries. The severity of periodontitis is inversely related to gestational age at delivery and birth weight of infant. Thus, periodontitis is suggested to be a modifiable risk factor for preterm and low birth deliveries.

\section{Funding: No funding sources Conflict of interest: None declared \\ Ethical approval: The study was approved by the Institutional Ethics Committee}

\section{REFERENCES}

1. Williams. Preterm Labour. In: Cunningham, eds. Williams Obstetrics, 24th ed. New York: McGraw Hill; 2014: 829-830. 
2. World Health Organization. The incidence of low birth weight: an update. Weekly Epidemiological Record. 1984;59(27):205-11.

3. Ovadia R, Zirdok R, Diaz-Romero RM. Relationship between pregnancy and periodontal disease. Med Biol. 2007;14(1):10-4.

4. Jacob PS, Nath S. Periodontitis among poor rural Indian mothers increases the risk of low birth weight babies: a hospital-based case control study. J Periodontal Implant Sci. 2014;44(2):85-93.

5. Offenbacher S, Katz V, Fertik G, Collins J, Boyd D, Maynor G, et al. Periodontal infection as a possible risk factor for preterm low birth weight. J Periodontol. 1996;67:1103-13.

6. Offenbacher S, Jared HL, O'reilly PG, Wells SR, Salvi GE, Lawrence HP, et al. Potential pathogenic mechanisms of periodontitis-associated pregnancy complications. Ann Periodontol. 1998;3(1):233-50.

7. Tellapragada C, Eshwara VK, Bhat P, Acharya S, Kamath A, Bhat $\mathrm{S}$, et al. Risk factors for preterm birth and low birth weight among pregnant Indian women: a hospital-based prospective study. J Preventive Med Pub Heal. 2016;49(3):165.

8. El-Gharib MN, Nassar MM, Elabyary MT, Elhawary TM, Elshourbagy SH. Link between periodontal diseases, inflammatory markers and preterm low birth weight infants. Clin Med Insights Reproductive Heal. 2010;4:CMRH-S5886.

9. Lopez NJ, Da Silva I, Ipinza J, Gutiérrez J. Periodontal therapy reduces the rate of preterm low birth weight in women with pregnancy-associated gingivitis. J Periodontol. 2005;76:2144-53.

10. Martínez-Martínez RE, Moreno-Castillo DF, LoyolaRodríguez JP, Sánchez-Medrano AG, San MiguelHernández JH, Olvera-Delgado JH, et al. Association between periodontitis, periodontopathogens and preterm birth: is it real?. Arch Gynecol Obstetrics. 2016;294(1):47-54.

11. Bhargava SK, Sachdev HP, Ramji S, Iyer PU. Low birthweight: aetiology and prevention in India. Ann Tropical Paediatrics. 1987;7(1):59-65.

12. Collins Jr JW, David RJ, Handler A, Wall S, Andes S. Very low birthweight in African American infants: the role of maternal exposure to interpersonal racial discrimination. Am J Pub Heal. 2004;94(12):2132-8.
13. López NJ, Smith PC, Gutierrez J. Higher risk of preterm birth and low birth weight in women with periodontal disease. J Dental Res. 2002;81(1):58-63.

14. Mitchell-Lewis D, Engebretson SP, Chen J, Lamster IB, Papapanou PN. Periodontal infections and preterm birth: early findings from a cohort of young minority women in New York. Euro J Oral Sci. 2001;109(1):34-9.

15. Dempsey R, Ashmead G, Bissada N, Clapp J, Amini $\mathrm{S}$. Periodontitis and preterm labor. Am J Obstet Gynecol. 2000;182:82.

16. Romero BC, Chiquito CS, Elejalde LE, Bernardoni CB. Relationship between periodontal disease in pregnant women and the nutritional condition of their newborns. J Periodontol. 2002;73(10):1177-83.

17. Marin C, Segura-Egea JJ, Martínez-Sahuquillo Á, Bullón P. Correlation between infant birth weight and mother's periodontal status. J Clin Periodontol. 2005;32(3):299-304.

18. Radnai M, Gorzó I, Nagy E, Urbán E, Novák T, Pál A. A possible association between preterm birth and early periodontitis: Pilot study. J Clin Periodontol. 2004;31(9):736-41.

19. Davenport ES, Williams CE, Sterne JA, Sivapathasundram V, Fearne JM, Curtis MA. The East London study of maternal chronic periodontal disease and preterm low birth weight infants: study design and prevalence data. Ann Periodontol. 1998;3(1):213-21.

20. Mokeem SA, Molla GN, Al-Jewair TS. The prevalence and relationship between periodontal disease and pre-term low birth weight infants at King Khalid University Hospital in Riyadh, Saudi Arabia. J Contemp Dent Pract. 2004;5(2):40-56.

21. Dasanayake AP. Poor periodontal health of the pregnant woman as a risk factor for low birth weight. Ann Periodontol. 1998;3(1):206-12.

Cite this article as: Priyanka S, Koteshwara S, Subappa A. Prevalence of maternal periodontitis and its association with preterm and low birth weight infants: a hospital-based study. Int J Reprod Contracept Obstet Gynecol 2019;8:1767-74. 